encourages you to move quickly to pass bipartisan legislation to strengthen our nation's infrastructure, including specific provisions focused on the unique needs of rural communities and agriculture," the letter urged. "We live and work every day in rural America and deeply understand the realities these communities face in order to remain prosperous and vibrant. We also understand that rural communities' needs are unique, oftentimes differing greatly from the realities of our urban counterparts," the letter continued.

The coalition pointed out the important role that rural communities play in the American economyproviding "food and fiber for our country and the world, creating jobs for millions of Americans." The coalition called on the federal government to continue to not only provide-but to increase-infrastructure funding in rural communities.

Lastly, the letter pledged the coalition's support in looking for creative solutions that include federal, state, and local investments, as well as private sources of capital. "We stand ready to work with you ... to help identify and implement these vital rural infrastructure improvements," said coalition members.

Sheri Porter

AAFP News Department

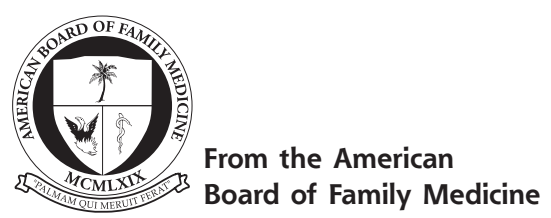

Ann Fam Med 2019;17:379-381. https://doi.org/10.1370/afm.2435.

\section{IMPROVING QUALITY IMPROVEMENT}

In February 2019, the Vision Committee recommended that the American Board of Medical Specialities

(ABMS) chart a new course for improvement in medical practice. ${ }^{1}$ Arguing that the Maintenance of Certification (MOC) requirement for improvement in medical practice had become onerous for some Diplomates and challenging to implement for many specialties, the Vision Committee called for the identification of new approaches to advancing practice while recognizing what Diplomates are already doing.

How did we start on the quality journey? Though systematic efforts to improve care date back at least as far as Semmelweis and Florence Nightingale, the 1999 and 2001 IOM reports "To Err is Human"2 and the "Crossing the Quality Chasm"3 transformed professional and legislative discourse about patient safety and the quality of care in the United States. The authors argued powerfully that error was common in health care, that it had important consequences for patients and that it was not primarily due to clinicians' mistakes but rather the lack of a culture of improvement and systems to prevent error and improve care. Closely following was empiric evidence of a dramatic gap between what all agreed should happen clinically and what actually happened in practice across the entire continuum of care. ${ }^{4}$ Thus, as ABMS developed the Maintenance of Certification program, a cornerstone was support of improvement of quality of care. ${ }^{5}$

What progress have we made in quality improvement in the 20 years since the publication of the original Institutes of Medicine report? An entire industry has developed around supporting this work: quality improvement goals and activities have been institutionalized in medical practices and hospital systems across the country. Reflecting this broad commitment, there are countless examples of improvement in measures of care across clinical settings ranging from primary care to inpatient care and long-term care. At the same time, however, the payers, agencies and others driving this process have worked largely independently from each other, resulting in an explosion of metrics, often with small differences that prevent comparisons across providers or geographies. Few measures have taken into account variations in patient populations and social determinants of health. Consequently, despite progress, major problems in care remain, and many promising quality improvement projects have failed to spread or be sustained. ${ }^{6}$ Moreover, the intrinsic motivation of physicians to improve the quality of care they provide has been challenged by administrative burden and often seemingly arbitrary metrics that vary by individual payers and organizations. Backlash is substantial, with both physicians and specialty organizations complaining about "meaningless" quality improvement activities.

So how will the American Board of Family Medicine proceed? Since its founding, ABFM has believed that assessment of cognitive expertise through periodic examination is insufficient for recertification. All Diplomates were required to recertify - an innovation across the Board Community - and all had to demonstrate excellence in practice, as measured by a practice audit, as well as continuing education and evidence of ethical professional conduct, in addition to an examination. ${ }^{7}$

In recent years, we have made increased performance improvement (PI) offerings available to Diplomates, aimed at increasing relevance by providing more options across a wide spectrum of practice types and scope. In particular, our Self-Directed pathway allows physicians who are already meaningfully participating in quality improvement $(\mathrm{QI})$ efforts in their 
practice or hospital system to gain certification credit for that work. The requirement to measure, intervene, and remeasure remains, but the documentation is much easier, and it eliminates the need to do "extra work" just for certification. The Self-Directed pathway is also useful for family physicians working in nontraditional office settings, such as emergency/urgent care, hospice and palliative medicine practices, or sports medicine, to define projects that will have the most impact and meaning for them. For physicians who are not already involved in ongoing improvement activities and have questions about how to develop their own practicebased initiatives, we offer guidance on how to do so, and what is needed to meet PI credit requirements.

For Diplomates working in larger groups or health systems, our Organizational PI pathway allows the organization to report on quality improvement initiatives in which they are already meaningfully involved, or to develop and conduct performance improvement activities that facilitate family physicians receiving PI activity credit for their participation. In practices that include physicians of different specialties, the ABMS multispecialty portfolio https://mocportfolioprogram. org/ similarly supports attainment of credit when meaningfully engaged in initiatives conducted in multispecialty groups. To support those physicians who teach medical students or residents in practice, we have partnered with the Society of Teachers of Family Medicine to provide Performance Improvement credit to preceptors who apply QI principles to improve their own teaching or engage learners in their clinical improvement efforts. ABFM staff regularly review and update options to provide Diplomates, and we continue to work with the AAFP and its state chapters as they develop new opportunities for Diplomates to identify gaps in their practice, obtain appropriate $\mathrm{CME}$, and work to improve their practices. Finally, ABFM has waived the performance improvement requirement for individuals who are not clinically active.

Over the last year, as we have engaged our Diplomates, it has become clear that communication of these options and changes can be more effective, and this has become a major area of focus for our Communication and Outreach efforts. In the near term, we will be improving navigation and updating our performance improvement options. We have heard from Diplomates that it is difficult to find which performance improvement activities best fit their practices, especially now that the opportunities have expanded so significantly. To assist with this, we are developing an online tool which will point Diplomates to activities that are customized for their practice type and scope.

Our long-term goal is to rethink performance improvement, working with Diplomates and partners in other organizations and specialties. Despite the progress of the last 20 years, we believe that America's health care continues to need dramatic improvement. As our new mission statement underscores, ABFM is committed to the triple aim of improving health, patient experience, and cost-effectiveness-and we believe that family physicians will need to continue to play a major role in this transformation.

As a first step, we must encourage more improvement across broader dimensions of care-not just clinical quality and safety, which are the most common focus today, but also the other dimensions originally identified in the original Institute of Medicine reports-patient-centeredness, timeliness, efficiency, and equity. While the ACO measure set touches on some of these areas, it does not go far enough. We will also need to address the emerging and expensive clinical problems that family physicians are uniquely positioned to address-multimorbidity, behavioral integration, substance abuse, social determinants of health, and fragmentation of care. Care of self is also an area in which many physicians want to address and should be included in options for improvement.

Which measures are chosen is critical. Part of the problem we face is the sharp rise in the number of metrics developed and required by government, commercial payers, and others. As has been well documented by the National Academies ${ }^{6}$, the total number of measures in use today is unknown but large; for example, the CMS Measure inventory alone logs nearly 2,238 different measures to date. Although many of these measures are of high quality and provide valid and useful information, many represent only slight variations of the same target. Furthermore, numerous measures in use today differ enough to prevent direct comparison among the various states, institutions, or individuals.

Thus, as a broader health care system, we will need to focus with intention on fewer, more important metrics; within primary care, we need to focus on measures that matter-measures that capture the unique contribution of personalized primary care. To meet this challenge, ABFM has begun to develop measures that better capture what is unique to family medicine and primary care, such as continuity, comprehensiveness, and patient centered outcomes. Early reports are promising ${ }^{8,9}$ and as new measures are evaluated and taken up by insurers, measuring and improving what we do will become more meaningful to practicing family physicians. Given increasing evidence of the impact of social determinants of health outcomes, we are also working with partners to identify and measure social factors that should contribute to risk-adjustment for core metrics and for payment. As new metrics are approved and adopted by others, we will all need to 
work together to develop new approaches to improving the care that matters most.

We know that family physicians across the country are doing creative work to improve care for their patients and their communities. We look forward to learning from you about how we can best support your work. It takes a village to improve quality-and to help heal health care.

Warren P. Newton, MD, MPH, Elizabeth Baxley, MD, American Board of Family Medicine Ann Lefebvre, MSW, CPHQ, Soutb Carolina AHEC

\section{References}

1. Vision Committee. Continuing Board Certification: Vision for the Future Commission. February 12, 2019.

2. Institute of Medicine. To Err is Human: Building a Safer Health System. Washington, DC: National Academy Press; 1999.

3. Institute of Medicine. Crossing the Quality Chasm: A New Health System for the 21st Century. Washington, DC: National Academy Press; 2001

4. McGlynn EA, Asch SM, Adams J, et al. The quality of health care delivered to adults in the United States. N Engl J Med. 2003;348(26): 2635-2645.

5. Nora LM. Advancing quality health care through continuing American Board of Medical Specialties board certification. J Am Board Fam Med. 2013;26(6):620-622.

6. Institute of Medicine Committee on Core Metrics. Vital Signs: Core Metrics for Health and Health Care Progress. Washington, DC: National Academies Press; 2015.

7. Adams D. American Board of Family Practice: A History Lexington, KY: American Board of Family Practice; 1999.

8. Bazemore A, Petterson S, Peterson LE, Phillips RL Jr. More comprehensive care among family physicians is associated with lower costs and fewer hospitalizations. Ann Fam Med. 2015;13(3):206-213.

9. Bazemore A, Petterson S, Peterson LE, Bruno R, Chung Y, Phillips RL Jr. Higher primary care physician continuity is associated with lower costs and hospitalizations. Ann Fam Med. 2018;16(6):492-497.

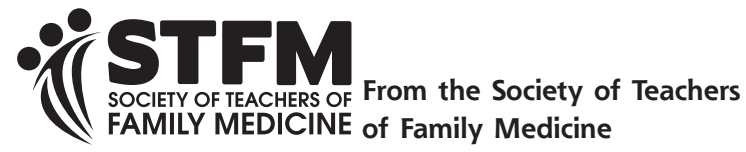

Ann Fam Med 2019;17:381-382. https://doi.org/10.1370/afm.2433.

\section{STFM RELEASES NEW MEDICAL SCHOOL RESOURCES}

The Society of Teachers of Family Medicine (STFM) has released multiple new resources for both students and faculty at medical schools.

\section{Medical School Faculty Fundamentals Certificate Program}

According to a 2012 study, new faculty identify 3 top priorities that contribute to their academic and professional success: teaching skills, scholarly activity, and career development. ${ }^{1}$ The Medical School Faculty Fundamentals Certificate Program was developed by the STFM Medical Student Education Committee, STFM staff, and subject matter experts to meet these needs for faculty with fewer than 5 years of professional experience.

This assessment-based online program includes selfled courses with assignments to provide foundational training for medical school faculty. Completion of the program requires approximately 35 hours and covers: the structure and requirements of medical education; how to be an effective and efficient faculty member the nuts and bolts of curriculum development and teaching; strategies for assessment, feedback, and evaluation of medical students; and academic advancement.

Each course within the program includes readings, videos, interactive modules, quizzes, and assignments. Topics include:

- Time Management in Your New Role

- Advising Medical Students

- Giving Feedback

- Curriculum Development

- Clinical Teaching Skills

- Classroom Teaching

- Assessment and Evaluation

- Scholarly Activity

- Writing for Publication

- Incorporating Students Into Your Clinical Workflow

- Medical Students in Difficulty: Academic and Behavioral Problems

- Academic Structure \& Professional Advancement

- LCME and COCA Requirements

- Establishing Professional Boundaries

Assignments require participants to apply what they've learned to their own roles and gather information about how the topics apply to their own institutions. For some course assignments, a faculty instructor provides personalized feedback.

To graduate, participants must complete all courses and assignments and pass a final exam. Graduates receive a certificate, a letter of congratulations noting the accomplishment, a letter to their Department Chair, and a press release to distribute locally.

\section{Student Onboarding Resources}

Free clerkship onboarding resources for students were released by STFM in April 2019. Departments, specialties, and health professions across the country are encouraged to use these new resources to standardize the preparation of students for clerkships and reduce administrative burden for community preceptors.

Schools can integrate the following resources into preclerkship curriculum by having their students: 